\title{
Vaccination perceptions of school employees in a rural school district
}

Janelle Macintosh

Brigham Young University - Provo

Karlen E. (Beth) Luthy

Brigham Young University - Provo, beth_luthy@byu.edu

Renea L. Beckstrand

Brigham Young University - Provo

Lacey M. Eden

Brigham Young University - Provo

Jennifer Orton

Brigham Young University - Provo

Follow this and additional works at: https://scholarsarchive.byu.edu/facpub

Part of the Other Nursing Commons, and the Public Health and Community Nursing Commons

\section{Original Publication Citation}

Macintosh, J. L. B., Luthy, K. E., Beckstrand, R. L., Eden, L. M., \& Orton, J.* (2014). Vaccination perceptions of school employees in a rural school district. Vaccine, 32(37), 4766-4771.

\section{BYU ScholarsArchive Citation}

Macintosh, Janelle; Luthy, Karlen E. (Beth); Beckstrand, Renea L.; Eden, Lacey M.; and Orton, Jennifer, "Vaccination perceptions of school employees in a rural school district" (2014). Faculty Publications. 5246.

https://scholarsarchive.byu.edu/facpub/5246

This Peer-Reviewed Article is brought to you for free and open access by BYU ScholarsArchive. It has been accepted for inclusion in Faculty Publications by an authorized administrator of BYU ScholarsArchive. For more information, please contact ellen_amatangelo@byu.edu. 


\title{
Vaccination perceptions of school employees in a rural school district
}

\author{
Janelle Macintosh, Karlen E. Luthy*, Renea L. Beckstrand, Lacey M. Eden, Jennifer Orton \\ Brigham Young University, College of Nursing, 500 SWKT, Provo, UT 84602, United States
}

\section{A R T I C L E I N F O}

\section{Article history:}

Received 21 March 2014

Received in revised form 13 May 2014

Accepted 6 June 2014

Available online 10 July 2014

\section{Keywords:}

Vaccine

Immunization

School employees

Influenza

MMR

Policy

\begin{abstract}
A B S T R A C T
Background: There continues to be a need for increases in adult vaccination rates, especially among those working in environments which may easily become communicable disease outbreak centers, such as school employees in the school environment. The purpose of this study was to evaluate why rural Utah school employees were non-compliant with the influenza and measles, mumps, and rubella (MMR) vaccines, as well as to identify their views on mandatory vaccination policies.

Methods: A questionnaire was distributed to all school employees in a rural Utah school district. Data analysis included frequencies and measures of central tendency and dispersion for quantitative items and theme identification for qualitative items.

Results: Only $51 \%$ of school employees were adequately vaccinated for influenza. Reasons for noncompliance with the influenza vaccine included inconvenience, lack of perceived need, and questionable vaccine efficacy. There were 39.3\% school employees who had not received an MMR during adulthood, which was commonly attributed to lack of knowledge regarding the need for this vaccine. Almost half (45.7\%) of school employees believed a mandatory vaccination policy should be instituted, although $24.2 \%$ of school employees were opposed to mandatory adult vaccination policies. Reasons for opposing vaccination mandates included violation of personal choice, lack of perceived vaccination safety and efficacy, lack of perceived need for adult vaccines, and vaccine cost.

Conclusions: Suboptimal vaccination rates of school employees may negatively affect the health and wellbeing of individuals in the school environment. School employees report a variety of beliefs regarding the influenza and MMR vaccines. While over half of school employees support mandatory vaccination policies for adults working in the school environment, those opposing such a policy report concerns regarding violation of personal choice. Public health officials and school administrators should coordinate efforts to increase vaccination rates among adults in the school environment.
\end{abstract}

(C) 2014 Elsevier Ltd. All rights reserved.

\section{Introduction}

Since the introduction of vaccinations, vaccine-preventable diseases have decreased by $98 \%$ for diseases such as smallpox, diphtheria, measles, mumps, and rubella [1]. However, in order to continue the low incidence of vaccine-preventable diseases, high vaccination rates must be maintained. To maintain adequate vaccination rates in the United States of America (U.S.), all 50 states have legislated mandates for childhood vaccinations before enrolling in public school [2,3]. Childhood vaccination compliance rates for American school-age children are closely monitored and, as a result, very high [4]. In fact, nationwide, Americans maintain $90 \%$ childhood vaccination rates for vaccines such as measles, mumps, and rubella (MMR), polio, hepatitis B, and varicella [5].

\footnotetext{
* Corresponding author. Tel.: +1 801422 6683; fax: +1 8014220536

E-mail address: beth_luthy@byu.edu (K.E. Luthy).
}

In contrast to the success of America's vaccination rates among children, U.S. adult vaccination rates remain suboptimal. For example, in 2012 only $14.4 \%$ of American adults were adequately vaccinated for tetanus, diphtheria, and pertussis [6]. For influenza, an estimated $40.4 \%$ of adults over 18 were vaccinated during the 2010-2011 influenza season [7]; adults 18-49 and 50-64 years rates were estimated at $30.5 \%$ and $44.5 \%$, respectively [7]. Many American adults are unsure of their vaccination status [8] and consequently, are incompletely protected against highly virulent diseases such as measles, pertussis, and influenza [9]. In fact, over 40,000 adult deaths per year are caused by a vaccine-preventable illness [1]. However, unvaccinated or undervaccinated adults affect much more than the adult individual as adults can serve as carriers for infectious disease, spreading vaccine-preventable communicable diseases to others in the community.

Vaccinations are mandated for a few adult employees, such as health care workers, who are at risk for contracting and spreading communicable diseases within populations [10]. Similarly, school 
employees are also in a position where they can easily contract and spread vaccine-preventable communicable diseases [11]. School employees are a significant group in the adult population with an estimated 7 million employees at more than 130,000 public and private schools in the U.S. [12]. Consequently, schools may easily become communicable disease outbreak centers due to factors such as dense populations, confined environments, and frequent personal contact among students, faculty, and staff $[12,13]$.

Low school employee vaccination rates have proven to be costly for school districts during communicable disease outbreaks. For example, in 2011 there was a measles outbreak in a school district in Salt Lake City, Utah. School employees exposed to measles who had not received the adult MMR booster or were unaware of their vaccination status were quarantined and replaced with substitutes costing the school district approximately $\$ 10,000$ [14]. School employees and their family members also experienced personal costs including unforeseen medical expenses, loss of wages, and time off work [14].

There continues to be a need for increases in adult vaccination rates, including school employees. Therefore, it is necessary to understand why school employees have not been vaccinated against some highly virulent diseases such as measles and influenza. Furthermore, it would be helpful to evaluate school employees' perceptions regarding a mandatory vaccination policy. The purpose of this study is to evaluate why school employees have not received the adult MMR vaccine or an annual influenza vaccine and to identify views on vaccination mandates for school employees in a rural school district in Utah.

\subsection{Research questions}

1. What are the reasons that rural Utah school employees are not up-to-date on the influenza vaccination?

2. What are the reasons that rural Utah school employees are not up-to-date on the MMR vaccination?

3. What are the perceptions of rural Utah school employees regarding mandatory vaccinations?

\section{Materials and methods}

Prior to data collection, Institutional Review Board approval was obtained for this nonexperimental mixed-method study. Prior to questionnaire distribution, the school district superintendent reviewed the questionnaire.

\subsection{Setting}

The rural school district, located in Northern Utah, was selected due to the diversity of schools. The entire school district contained only two urbanized clusters with populations greater than 2500 people. The remaining cities encompassed by the school district had population concentrations of less than 2500 people, thereby meeting the definition of a rural community [15]. The questionnaire was distributed among all schools in the school district: pre-school, elementary, junior high school, and high school, as well as the district office building.

\subsection{Subjects}

A convenience sample of 1400 school district employees was invited to participate in the study. Both full- and part-time individuals employed by the rural school district were eligible to participate. Participants included faculty and staff from all schools, as well as employees at the district office building, technology department, and transportation department. Excluded from participation were non-paid volunteers.

\subsection{Instrument}

The questionnaire was previously piloted in an urban Utah school district. The original questionnaire was evaluated for face validity by a team of public health and nursing experts and was pre-piloted. The content of the questionnaire for rural Utah school employees was not reevaluated for validity, although it was slightly modified for the purposes of this rural study. The revised questionnaire was two pages and included 10 yes/no, 7 multiple choice, 2 open-ended, and 7 demographic questions. The results of 2 multiple choice questions, (1) if you have not received the influenza immunization, why not; and (2) if you have not received the MMR immunization as an adults, why not, as well as 1 open-ended question, (1) if no, why would you not want adult immunizations to be mandatory for school employees, are reported in this study. Data for the remaining questions are reported elsewhere.

The multiple choice questions evaluated the school employee's reasons for declining the annual influenza and the adult MMR vaccinations. The multiple choice items for influenza and MMR vaccinations included choices such as: too costly, did not have time/forgot, not required by employer, was not sure I needed to get one, allergic, did not believe it would help, worried about side effects, it would make me sick, I am healthy and do not need it, and shots hurt. Participants were encouraged to select all reasons that were applicable. An "Other" section was provided for both influenza and MMR questions where additional reasons for non-vaccination could be written. A final open-ended question allowed unrestricted responses by participants regarding why adult vaccinations should not be mandatory for school employees.

\subsection{Procedures}

After gaining the approval of the school district superintendent, each school secretary and one school district secretary was contacted and acquainted with the study. Questionnaire packets were distributed to schools and the district secretary. Secretaries placed questionnaire packets in each school employee's mailbox. Questionnaire packets contained an informed consent document, questionnaire, self-addressed and pre-paid return envelope, and $\$ 1.00$ as participation compensation. Consent was implied by returning the questionnaire. A follow-up email reminding employees to complete and return the questionnaire was sent by the school secretaries two weeks after packet distribution. Recipients kept the $\$ 1.00$ regardless of participation.

\subsection{Data analysis}

Data were entering into an SPSS 21 (SPSS Inc., Chicago, Ill, 2012) database. Two independent researchers, one of whom read the responses from each questionnaire while the other researcher reviewed the entered data, ensured the accuracy of data entry. The primary investigator examined unclear responses to determine the correct response. Data analysis for the quantitative multiple-choice questions included frequencies and measures of central tendency and dispersion. Two independent researchers analyzed the openended question and "Other" responses separately for qualitative themes. The two researchers then met, compared themes, and identified the most common themes.

\section{Results}

Questionnaires were delivered to 1346 full- and part-time school employees in the rural Utah school district. Returned 
Table 1

Demographics of rural school employees.

\begin{tabular}{lcc}
\hline Demographic & $n(\%)$ & $M(\mathrm{SD})$ \\
\hline Sex & $172(21.4)$ & \\
Male & $631(78.6)$ & \multirow{2}{*}{$49(11.06)$} \\
Female & & \\
Age (years) & $774(96.8)$ & \\
Ethnicity & $13(1.6)$ & \\
Caucasian & $13(1.6)$ & \\
Hispanic & $360(44.7)$ & \\
Non-Hispanic & $175(21.7)$ & \\
Type of school & $144(17.9)$ & \\
Elementary & $126(15.7)$ & \\
Middle/junior high & & \\
High school & $350(43.8)$ & \\
District office & $111(13.8)$ & \\
Current occupation & & \\
Teacher & $88(11.0)$ & \\
Administrator/office & $222(27.8)$ & \\
worker/secretary/counselor & & \\
Education specialist/computers/librarian & $29(3.6)$ & \\
Support staff/lunch & & \\
worker/nurse/custodian/tracker & $555(69.1)$ & \\
Other & $240(29.9)$ & \\
Type of employment & & \\
Full time & & \\
Part time & & \\
Other (on-call) & & \\
Years worked in school district (years) & & \\
\hline
\end{tabular}

questionnaires $(n=835)$ constituted a $62 \%$ response rate. The majority of participants were female ( $n=631,78.6 \%)$. Participants mean age was 49 (SD 11.06). The average length of time worked in the school district was 12.9 years (SD 8.80). Remaining demographic information is presented in Table 1.

\subsection{Reasons for declining adult vaccinations}

\subsubsection{Influenza}

The majority of participants $(n=425,51 \%)$ reported not receiving the influenza vaccine during the 2011-2012 influenza season. The most frequently selected reasons for not receiving the influenza vaccine included "didn't believe the immunization would help," "didn't have time/forgot," and "I am healthy and don't need it." Frequency and percent for all responses are presented in Table 2. Since questioning the efficacy of the influenza vaccine was the most common answer, a logistic regression was performed on individuals who did not receive a flu vaccination. Belief that the vaccination was ineffective was the outcome variable. Demographic variables of age, occupation, full-time status, gender, and ethnicity were included as predictor variables. None of the demographic variables were significant predictors of the belief that the vaccine was ineffective.

Participants also wrote in an additional 82 comments regarding reasons for being inadequately vaccinated against influenza. Comments were categorized into themes: (1) inconvenient to take time off work to get the vaccination at a clinic; (2) did not

Table 2

Influenza vaccinations.

\begin{tabular}{lc}
\hline Reason not received $(n=834)$ & $n(\%)$ \\
\hline Do not believe immunizations would help & $112(13.4)$ \\
Did not have time/forgot & $108(12.9)$ \\
I am healthy and do not need it & $91(10.9)$ \\
Worried about side effects & $82(9.8)$ \\
It makes me sick & $72(8.6)$ \\
Not required by employer & $33(4.0)$ \\
Was not sure I needed one & $28(3.4)$ \\
Shots hurt & $20(2.4)$ \\
Too costly & $20(2.4)$ \\
I am allergic & $13(1.6)$ \\
\hline
\end{tabular}

Table 3

MMR vaccinations.

\begin{tabular}{lc}
\hline Reasons not received $(n=834)$ & $n(\%)$ \\
\hline Was not sure I needed one & $382(45.8)$ \\
Not required by employer & $45(5.4)$ \\
I am healthy and do not need it & $44(5.3)$ \\
Did not have time/forgot & $36(4.3)$ \\
Do not believe immunizations would help & $28(3.4)$ \\
Worried about side effects & $26(3.1)$ \\
Shots hurt & $15(1.8)$ \\
Too costly & $10(1.2)$ \\
It makes me sick & $4(0.5)$ \\
I am allergic & $1(0.1)$ \\
\hline
\end{tabular}

perceive the need for influenza vaccination; and (3) belief that the influenza vaccine was ineffective. The inconvenience of getting the influenza vaccine was commonly demonstrated in comments such as "not offered at school this year-inconvenient to get somewhere else," and "inconvenient location." The lack of perceived need was expressed in comments such as "have never had flu in the past," and "I normally do not get sick in the winter." A belief that the influenza vaccine is not effective was indicated in responses such as "I never get flu shots because they don't help," and "too many strains for [one] immunization."

\subsection{2. $M M R$}

Participants were also asked about MMR vaccination status and beliefs. Over a third of participants ( $n=328,39.3 \%)$ reported not receiving an MMR vaccination as an adult. The most frequently selected reason for not receiving the adult MMR vaccine was "Wasn't sure if I needed to get one." Since this was the most common answer, a logistic regression was performed on individuals who did not receive an adult MMR vaccination. "Not sure I needed to get one" was the outcome variable, and demographic variables of age, occupation, full-time status, gender, and ethnicity were included as predictor variables. None of the demographic variables were significant predictors of knowledge of need for an adult MMR vaccination. Frequency and percentage for all responses are present in Table 3.

Although not all participants included comments, an additional 126 responses were reported for not receiving the MMR vaccination. The most common themes were identified: (1) unaware that an adult MMR vaccine was available or needed; (2) already immune because had the diseases as a child; and (3) did not perceive the need to receive the adult MMR vaccine in addition to the childhood vaccination. Participants unaware of availability or need of the adult MMR vaccine expressed this in comments such as "didn't know I needed one," and "I've never heard of adult MMR." Previous immunity from having the diseases as a child was demonstrated in responses such as "had measles, mumps, and rubella as a child," and "I've already had these illnesses." A perception that the adult MMR vaccine was unnecessary was demonstrated by responses such as "think my child one is enough," and "thought you only needed it once."

\subsection{Mandatory vaccine perceptions}

Of those who responded (missing, $n=12$ ) about their beliefs regarding vaccination mandates for all school employees, $24.2 \%$ ( $n=199)$ replied "no," although almost half of participants $(n=376$, $45.7 \%$ ) believed school employees should have mandatory vaccination requirements. Another $30.1 \%(n=248)$ were undecided about vaccination mandates for school employees. To examine any association between occupation and support for mandatory vaccination requirements, a chi-square test of association was performed. Current occupation was the independent variable and support for 
mandatory vaccination requirements was the dependent variable with three levels (no, yes, undecided). The result was not significant indicating no association between occupation and support for mandatory vaccination requirements.

To examine any association between age and support for mandatory vaccination requirements, a one-way ANOVA was conducted. The test was not significant indicating no association between age and support for a mandatory vaccination policy. Chi-square tests of association were conducted to examine the relationships between demographics and support for mandatory vaccination. Crosstabs for profession, employment status, ethnicity, and school type were not significant. However the crosstab for gender with support for vaccination requirements was significant $\chi^{2}(d f=2, n=797)=7.4, p=.025$, Cramer's $V=.096$.

Examination of standardized residuals indicates males were overrepresented (std. res. $=1.9$ ) among those opposing mandatory vaccination requirements as well as underrepresented (std. res $=-1.5$ ) among those undecided. Females were somewhat underrepresented (std. res. $=-1.0$ ) in those showing lack of support for mandatory vaccination requirements.

If participants did not believe that schools should have mandatory vaccination for employees, they were asked to provide reason(s). Several participants ( $n=167$ of $834,20 \%$ ) wrote in a reason why vaccines should not be mandatory for school employees. Responses were categorized into four themes: (1) vaccinations are a personal choice, particularly for adults; (2) there are no guarantees for the safety or efficacy of vaccines; (3) adult vaccinations are unnecessary; and (4) vaccine cost.

The belief that vaccinations are a personal choice for adults was by far the most frequent response. This belief was demonstrated with statements such as "as adults, we can make that decision ourselves," "adults should be able to decide whether or not to get immunizations if they know the consequences," and "people need to have a choice." Concerns about the safety and efficacy of vaccines were expressed statements such as "I am not convinced that immunizations are completely safe," and "it seems people that get immunized miss many more days than those who do not." Belief that adult vaccinations are unnecessary was identified in several responses such as "if you had them as a child that should be sufficient" and "because I don't believe there should be a law if there is not a problem." Lastly, the cost of mandatory vaccinations was addressed in responses such as "because I don't want the extra cost" and "if it is required we often end up having to pay for it." See Table 4 for qualitative themes and sample quotes.

\section{Discussion}

\subsection{Influenza vaccine}

The influenza vaccination beliefs reported by the rural school employees in this study were similar to beliefs of other adult populations. In fact, the beliefs and reasons adults are noncompliant with influenza vaccination have changed very little over the past 20 years [16]. The primary reason participants of this study did not receive an influenza vaccine was the belief that the influenza vaccine did not prevent them from contracting influenza. Similarly, doubting vaccine efficacy was also reported as one of the top reasons that other adult populations did not receive the influenza vaccine $[17,8]$.

Additionally, school employees in this study reported not having time or simply forgetting to get an annual influenza vaccination. Unfortunately, inconvenience of receiving the influenza vaccination is a common barrier to adequate vaccination in many adult populations $[16,17]$, indicating a potential need for mobile vaccination clinics. Providing vaccination clinics at workplaces increases
Table 4

Qualitative themes opposing mandatory immunizations.

\begin{tabular}{ll}
\hline Theme & Sample quote \\
\hline Violates personal choice & $\begin{array}{l}\text { "everyone has the choice to get immunized" } \\
\text { "everyone should be free to choose" } \\
\text { "it’s an individual decision" } \\
\text { "some people cannot have them" } \\
\text { "I believe that here should be exemptions just } \\
\text { as there are for children" } \\
\text { "allergies, religion" } \\
\text { "because I know of some people who have bad } \\
\text { reactions to them. I believe it is a personal } \\
\text { decision" } \\
\text { "do not see a need" } \\
\text { "I assume they have has the required } \\
\text { immunizations during childhood and young } \\
\text { adult hood, making it unnecessary" } \\
\text { "these are childhood diseases" } \\
\text { "not sure it would help" } \\
\text { "I guess it would depend on what the } \\
\text { immunization is" } \\
\text { "there are certain immunizations that I } \\
\text { wouldn't want to be required" } \\
\text { "I think some are good but not all. We are all } \\
\text { old enough and have built immune systems for } \\
\text { certain things" } \\
\text { "cost, convenience - if they were offered in a } \\
\text { convenient place for cheap I would do it" } \\
\text { "only if you pay for them" } \\
\text { "if they were free - yes" }\end{array}$ \\
Only some &
\end{tabular}

the vaccination rates among employees and minimizes the amount of days off work. Moreover, increased vaccination rates can prevent illness: illness in the workplace setting leads to a reduction of productivity and effectiveness of employees [18].

\subsection{MMR vaccine}

There are many misunderstandings about the need for an adult MMR booster. An overwhelmingly large number of rural school employees in this study reported a lack of awareness or knowledge regarding need for a second MMR vaccination. The current adult recommendations for MMR vaccine may be confusing to some. According to 2014 guidelines, adults born before 1957 are considered immune to measles and mumps. Adults born in 1957 or later should have at least one MMR vaccination, unless the vaccination is contraindicated or the adult can provide evidence of immunity to all three diseases. Two MMR vaccines are recommended for: (1) students in postsecondary educational institutions; (2) those working in health care facilities; or (3) those traveling internationally [19].

Further adding to possible confusion is the fact that recommendations for adult school employee MMR vaccinations may also differ from the national guidelines and from state-to-state. In Utah it is recommended that school employees born before 1957 receive 1 dose of MMR, which is more prescriptive than the national guidelines. Furthermore, Utah school employees born during or after 1957 should receive 2 doses of MMR [20], which includes a booster that may be unnecessary according to national guidelines. As a result, school employees may need assistance in reconciling state and national MMR vaccination guidelines.

\subsection{Mandatory school employee vaccination policies}

School employees expressed multiple concerns about mandatory vaccinations including efficacy of vaccines, need, and cost. Men seem to be more opposed to mandatory vaccination requirements and fewer men were undecided when compared to women. The greatest concern reported by both genders was that mandatory vaccinations would violate personal choice and right to health 
decisions. Essentially, many participants were opposed to the elimination of personal choice subsequent to mandatory vaccinations. Interestingly, however, school employees in favor of adult vaccination mandates and those who were undecided, far outweighed those who outright rejected vaccination mandates. Similar to vaccination mandates for school-aged children, the purpose of mandating vaccinations in the school environment is not to eliminate personal choice but to increase protection against preventable diseases, thereby improving the health of individuals in the school and the community.

\subsection{Recommendations for public health officials and school administrators}

Public health officials and school administrators can play an integral role in increasing the vaccination rates among not only students, but school employees as well. The need for additional education regarding influenza and the need for a second MMR was apparent in this study. Fortunately, adult vaccination education programs have thus far been successful in increasing overall vaccination rates [21]. Thus, we recommend a collaborative effort between public health officials and school administrators, who can work together on educational campaigns regarding adult vaccinations for school employees, specifically regarding influenza and MMR.

A common concern raised by participants was the inconvenience of seeking and receiving vaccinations. School located vaccination clinics have been shown to be effective at increasing uptake of the seasonal influenza vaccine [22]. Public health officials and school administrators could implement school located vaccination clinics for all vaccinations, including seasonal influenza. However, support from public health officials, administration, and school nurses is paramount in the success of school located vaccination clinics [23]. Additionally, it is recommended that public health officials and school administrators open a dialog regarding the need for mandatory school employee vaccination policies and how to institute such policies.

\subsection{Limitations}

The sample of this study was gathered through convenience sampling and may not represent the school employee population. The study setting was conducted in a rural school district, and the results may not accurately represent the employees in urban or suburban school districts. Volunteers and other non-paid positions were not included as participants in this study. The sample of this study included employees from public schools and findings may not apply to employees at private or charter schools.

Additionally, participants of this study were not questioned about positive enforcers of vaccination choices. Future research could include asking participants not only why they chose to refuse a vaccination but also asking participants why they choose to receive a vaccination.

\section{Conclusion}

Low vaccination rates for highly virulent diseases such as influenza, measles, mumps, and rubella could have an especially negative effect on the health and well-being of individuals in the school environment. Nevertheless, low adult vaccination rates continue to be a concern. School employees report various beliefs regarding the influenza and MMR vaccinations and barriers to remaining current on their vaccines. Many school employees have inadequate or inaccurate information about the influenza and MMR vaccines. Furthermore, some school employees are opposed to mandatory vaccine policies for adults because of a perceived risk to personal choice. Public health officials are in a prime position to decrease vaccine-related misconceptions, provide accurate information about efficacy and need for adult vaccinations, and emphasize benefits of a mandatory vaccination policy for school employees. It is recommended school administrators consider the positive impact mandatory school employee vaccine policies can have on the health and well-being of all members of the school environment. With such school district vaccination policies, the vaccination rates among school employees will likely increase.

\section{Conflict of interest statement}

The authors have no financial or personal relationships with other people or organizations that could inappropriately influence the research. Funding was provided by the Brigham Young University College of Nursing. Other than providing financial support, the sponsor was uninvolved in study design, the collection, analysis and interpretation of data, the writing of the report, and the decision to submit the article for publication.

\section{References}

[1] American Academy of Microbiology. Adult vaccines: a grown up thing to do. Washington, DC: American Academy of Microbiology; 2012. Retrieved from http://www.osaicri.org/AdultReport.pdf

[2] Centers for Disease Control and Prevention. State vaccination requirements; 2011. Retrieved from http:/www.cdc.gov/vaccines/vac-gen/laws/ state-reqs.htm

[3] Ciolli A. Mandatory school vaccinations: the role of tort law. Yale J Biol Med 2008;81(3):129-37.

[4] Stokely S, Stanwyck C, Avey B, Greby S. Vaccination coverage among children in Kindergarten: United States 2009-2010 school year. Morb Mortal Wkly Rep 2011;60(21):700-4.

[5] Brown E. CDC reports on U.S. vaccination rates, recent measles outbreaks; 2013 September 12. Retrieved from http://www.latimes.com/science/sciencenow/ la-sci-sn-cdc-measles-vaccines-20130912,0,3434309.story

[6] Williams WW, Lu PJ, Singleton JA, Bridges CB, Wortley PM, Immunization Services Division, Centers for Disease Control and Prevention. Adult vaccination coverage-United States, 2010. Morb Mortal Wkly Rep 2012;61(04):66-72.

[7] Centers for Disease Control and Prevention. Seasonal influenza (flu); 2011. Retrieved from http://www.cdc.gov/flu/fluvaxview/coverage_1011estimates. htm

[8] Johnson DR, Nichol KL, Lipcynski K. Barriers to adult immunization. Am J Med 2008;121(7):S28-35

[9] Children's Hospital of Philadelphia. Immunizations: vaccines and adults. A lifetime of health. Philadelphia, PA: Children's Hospital of Philadelphia; 2010

[10] Centers for Disease Control and Prevention. Recommended vaccines for healthcare workers; 2013. Retrieved from http://www.cdc.gov/vaccines/adults/recvac/hcw.html

[11] Luthy KE, Houle K, Beckstrand RL, Macintosh J, Lakin RG. Vaccination perceptions and barriers of school employees: a pilot study. J Sch Nurs 2013:29(4):284-93.

[12] Gargano LM, Painter JE, Sales JM, Morfaw C, Jones LM, Murray D, et al. Seasona and 2009 H1N1 influenza vaccine uptake, predictors of vaccination, and selfreported barriers to vaccination among secondary school teachers and staff. Hum Vaccin 2011;7(1):89-95, http://dx.doi.org/10.4161/hv.7.1.13460.

[13] Mikolajczyk RT, Akmatov MK, Rastin S, Kretzschmar M. Social contacts of school children and the transmission of respiratory-spread pathogens. Epidemiol Infect 2008;136(6):813-22.

[14] Stewart K. Utah tallies costs as measles outbreak runs its course. Salt Lake Tribune; 2011, May. Retrieved from http://www.sltrib.com/sltrib/news/ 51831839-78/measles-outbreak-health-county.html.csp.

[15] United States Department of Agriculture. Economic research service. Rural definitions: data documentation methods - Utah; 2007. Retrieved from http://www.ers.usda.gov/datafiles/Rural_Definitions/StateLevel_Maps/ut.pdf

[16] Chapman GB, Coups EJ. Predictors of influenza vaccine acceptance among healthy adults. Prev Med 1999;29(4):249-62.

[17] Hollmeyer HG, Hayden F, Polant G, Buchholz U. Influenza vaccination of health care workers in hospitals-A review of studies on attitudes and predictors. Vaccine 2009;27(30):3935-44, http://dx.doi.org/10.1016/j.vaccine.2009.03.056.

[18] Nowalk MP, Lin CJ, Toback SL, Rousculp MD, Eby C, Raymund M, et al. Improving influenza vaccination rates in the workplace: A randomized trial. Am J Prev Med 2010;38(3):237-48, http://dx.doi.org/10.1016/j.amepre.2009.11.011.

[19] Centers for Disease Control and Prevention. Recommended adult immunization schedule, by vaccine and age group; 2014. Retrieved from http://www.cdc.gov/vaccines/schedules/hcp/imz/adult.html 
[20] Utah Department of Health. Utah school and childcare employee immunization recommendations; 2011. Retrieved from http://www.immunize-utah.org/ pdf/Utah\%20School\%.20and\%20Childcare\%20Employee\%20Immunization\%20 Recommendations.pdf.

[21] Kruspe R, Lillis R, Daberkow DW, Blais CM, Wilbright W, Gupta S, et al. Education does pay off: Pneumococcal vaccine screening and administration in hospitalized adult patients with pneumonia. J La State Med Soc 2003;155(6):325-31.
[22] Yoo BK, Humiston SG, Szilagyi PG, Schaffer SJ, Long C, Kolasa M. Cost effectiveness analysis of elementary school-located vaccination against influenza-results from a randomized controlled trial. Vaccine 2013;31(17):2156-64, http://dx.doi.org/10.1016/j.vaccine.2013.02.052.

[23] Hull HF, Ambrose CS. Current experience with school-located influenza vaccination programs in the United States: a review of the medical literature. Hum Vaccin 2011;7(2):153-60, http://dx.doi.org/10.4161/hv.7.2.13668. 